\title{
Model Expertise Management System di Universitas Negeri Semarang
}

\author{
Aji Purwinarko $^{1}$, YL Sukestiyarno ${ }^{2}$ \\ ${ }^{1}$ Jurusan Ilmu Komputer, FMIPA, Universitas Negeri Semarang \\ ${ }^{2}$ Jurusan Matematika, FMIPA, Universitas Negeri Semarang \\ Email: 'aji.purwinarko@mail.unnes.ac.id, ${ }^{2}$ yarno2009@yahoo.com
}

\begin{abstract}
Abstrak
Pemanfaatan sistem informasi sebagai penopang organisasi tidak dapat dipungkiri lagi, dimana setiap bagian dari organisasi diharapkan mampu memberikan pelayanan yang cepat dan akurat kepada setiap end user. Salah satu bentuk layanan sistem informasi tersebut adalah Expertise Management System (EMS). EMS dikembangkan di Universitas Negeri Semarang (UNNES) memiliki kemampuan untuk menyajikan data tentang pakar-pakar yang telah dimiliki UNNES kepada end user. Desain EMS melalui tahap prototype (analisis, perancangan, desain sistem, $D F D, E R D$, dan desain skema database), pemrograman, pengujian dan pemeliharaan. Melalui EMS ini pula, UNNES dapat menawarkan pakar-pakarnya untuk berkolaborasi dalam penelitian maupun kegiatan lainnya, sehingga dengan sendirinya akan memperkuat posisi UNNES di dalam persaingan tingkat regional maupun global.
\end{abstract}

Kata Kunci: Expertise management system, Expertise, Management system

\section{PENDAHULUAN}

Sebuah sistem informasi bertujuan untuk menyajikan informasi yang diperlukan dalam mengelola organisasi agar berjalan secara efektif dan efisien [1]. Sistem informasi membantu organisasi memfasilitasi pengumpulan, pencatatan, organisasi, pengambilan, dan penyebaran informasi. Pengetahuan yang terkumpul tergabung dalam kebijakan dan prosedur di dalam organisasi kemudian disebarluaskan kepada para 'pemangku kepentingan [2]. Salah satu bentuk sistem informasi tersebut adalah melalui Expertise Management System (EMS).

Definisi expertise adalah kepakaran [3], keterampilan atau pengetahuan yang dimiliki oleh seorang ahli [4]. Sehingga, EMS merupakan suatu sistem informasi yang menyajikan data mengenai keterampilan atau pengetahuan yang dimiliki oleh seorang ahli. EMS dapat membantu anggota organisasi menemukan orang lain untuk menjawab pertanyaan serta memperoleh informasi yang dibutuhkan untuk menyelesaikan aktivitas yang dikerjakan [5].

Melalui EMS yang dikembangkan di lingkungan Universitas Negeri Semarang (UNNES), diharapkan UNNES dapat menyajikan dan menawarkan pakar-pakar yang dimilikinya untuk berkolaborasi dalam penelitian maupun kegiatan lain, sehingga dengan sendirinya akan memperkuat posisi UNNES di dalam persaingan tingkat regional maupun global. Selain itu, EMS juga diharapkan menyajikan data yang akurat dan up to date [6]. 


\section{METODOLOGI}

Pengembangan EMS dilakukan dengan menggunakan model System Development Life Cycle $(S D L C)$ atau lebih dikenal sebagai waterfall model (model air terjun) [78]. Model ini terdiri dari beberapa tahap sebagai berikut.

\subsection{Analisis dan Definisi Persyaratan}

Batasan dan tujuan ditentukan melalui konsultasi dengan pengguna sistem dan persyaratan yang diperoleh didefinisikan secara rinci serta berfungsi sebagai spesifikasi sistem.

\subsection{Perancangan Sistem dan Perangkat Lunak}

Perancangan sistem dan perangkat lunak dapat digambarkan melalui beberapa hal berikut.

\subsubsection{Data Flow Diagram (DFD)}

DFD [9] digunakan sebagai model analisis sistem perangkat lunak yang diimplementasikan dengan pemrograman terstuktur. $D F D$ adalah representasi grafik yang menggambarkan aliran informasi dan transpormasi informasi yang diaplikasikan sebagai data yang mengalir dari input (masukan) dan output (keluaran). Berikut penjelasan lain mengenai $D F D$. (a) DFD Level 0 menggambarkan sebuah sistem yang akan dibuat sebagai suatu entitas tunggal yang akan berinteraksi dengan orang atau sistem yang lain, (b) DFD Level 1 merupakan hasil breakdown DFD Level 0 yang sebelumnya sudah dibuat dan (c) DFD Level 2 merupakan semua proses yang menyusun DFD Level 1.

\subsubsection{Entity Relationship Diagram (ERD)}

$E R D$ [10] merupakan suatu model yang digunakan untuk menggambarkan data dalam bentuk entitas, atribut, dan hubungan antar entitas. ERD tidak mencerminkan bentuk fisik, melainkan hanya bentuk konseptual. Kardinalitas relasi [11] dapat dinyatakan dengan banyaknya garis cabang atau dengan pemakaian angka (1 dan 1 untuk relasi satu-ke-satu, satu dan $\mathrm{N}$ untuk relasi satu-ke-banyak, atau $\mathrm{N}$ dan $\mathrm{N}$ untuk relasi banyak-ke-banyak).

\subsection{Implementasi dan Pengujian Unit}

Perancangan perangkat lunak direalisasikan sebagai serangkaian program atau unit program. Pengujian unit melibatkan verifikasi bahwa setiap unit telah memenuhi spesifikasinya.

\subsection{Integrasi dan Pengujian Sistem}

Unit program atau program individual diintegrasikan dan diuji sebagai sistem yang lengkapuntuk menjamin bahwa persyaratan sistem telah terpenuhi. 


\subsection{Pemeliharaan}

Pemeliharaan mencakup koreksi dari berbagai error yang tidak ditemukan pada tahap-tahap terdahulu, perbaikan atas implementasi unit sistem dan pengembangan pelayanan sistem, sementara persyaratan-persyaratan baru ditambahkan.

\section{HASIL DAN PEMBAHASAN}

\section{1. $D F D$}

Dalam DFD konteks EMS diperlihatkan beberapa hal sebagai berikut. (a) Pengguna yang dapat mengakses EMS adalah Tamu, Dosen dan Admin, (b) Tamu dapat mengakses data pakar, (c) Dosen dapat melakukan login sebagai dosen untuk mengubah kepakaran dan (d) Admin berperan sebagai pengelola EMS dapat login untuk menambahkan pengguna maupun mengubah password. DFD dari EMS seperti terlihat pada Gambar 1.

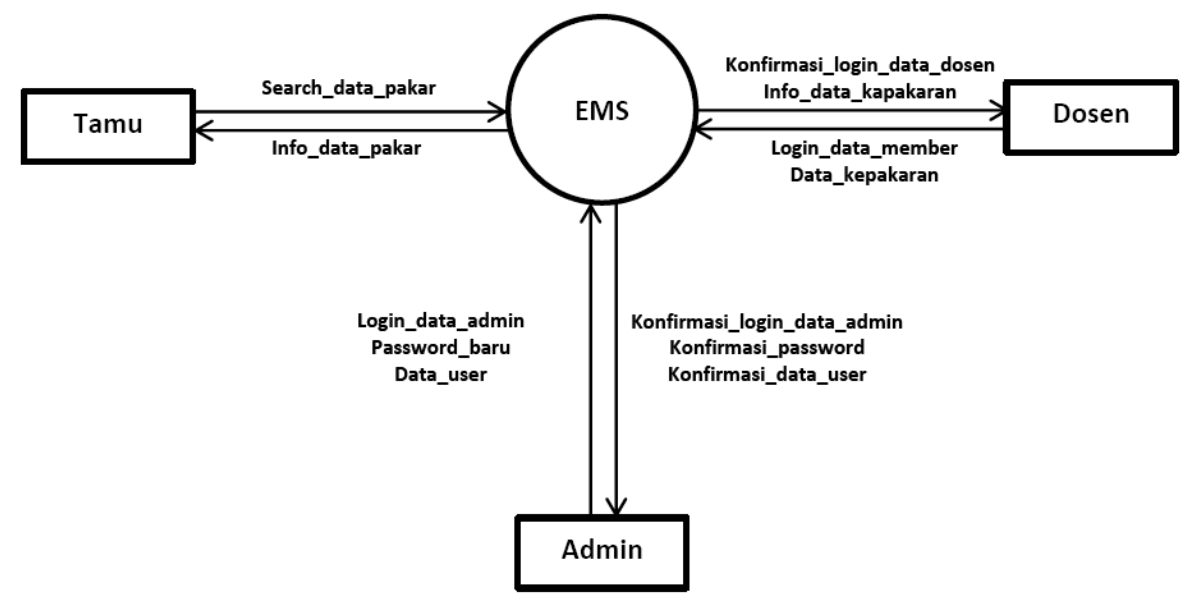

Gambar 1. Diagram konteks EMS

\section{2. $E R D$}

Di dalam ERD dari EMS diperlihatkan bahwa user mempunyai level, kemudian user dapat mengakses menu sesuai dengan level yang dimilikinya. User yang memiliki level dosen dapat mengubah data bidang ilmu dan sub bidang ilmu sesuai dengan kepakaran yang dimilikinya. User yang memiliki level prodi, dapat mengakses data dosen dalam prodi tersebut. ERD dari EMS ditunjukkan oleh Gambar 2. 


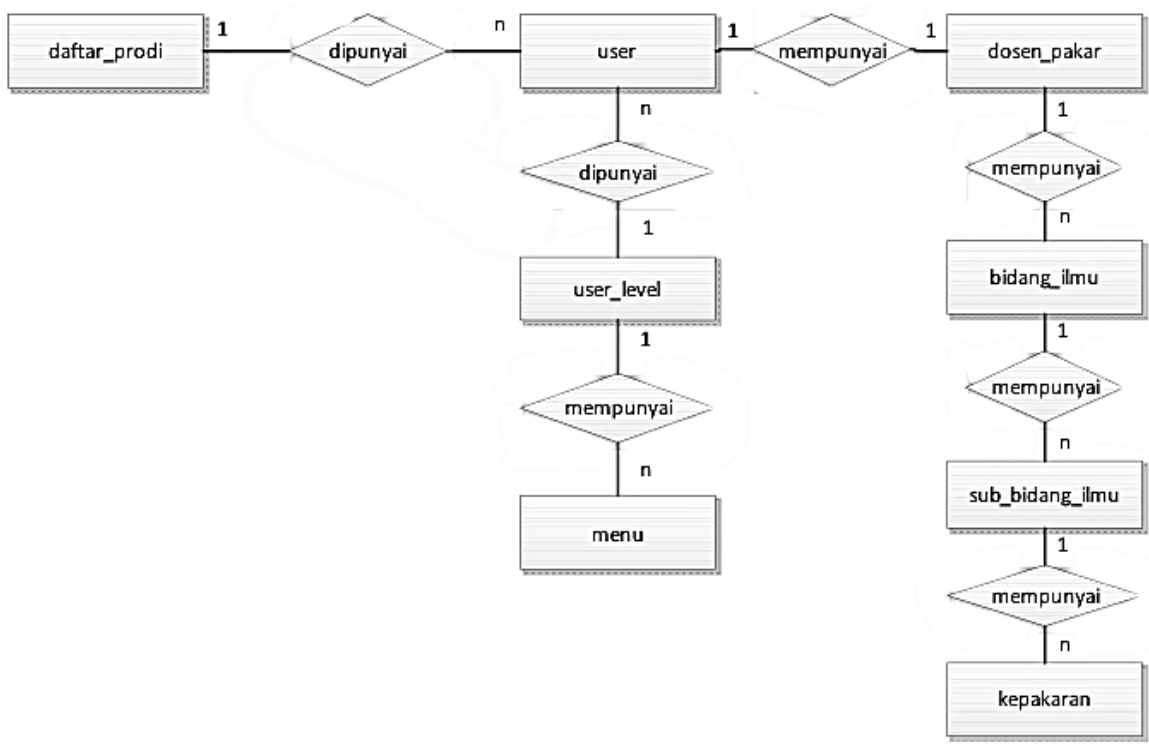

Gambar 2. $E R D$ dari $E M S$

\subsection{Skema Database}

$E R D$ dari EMS sebagai dasar dari pembuatan skema database. Entitas yang terdapat di dalam skema database disesuaikan dengan ERD. Berikut adalah skema database seperti diperlihatkan pada Gambar 3.

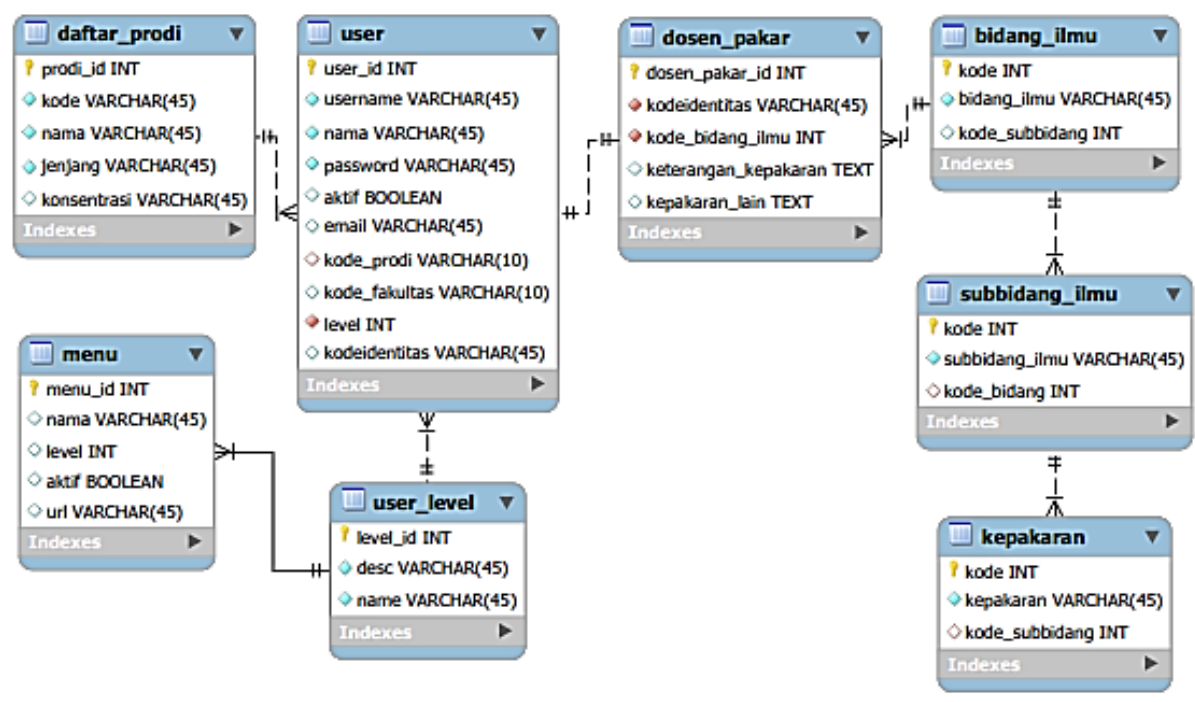

Gambar 3. Skema database dari EMS 


\subsection{Laman EMS}

Laman EMS terdiri dari beberapa laman utama. Laman login seperti ditunjukkan Gambar 4 merupakan laman yang digunakan untuk masuk ke dalam sistem. Laman pengguna seperti ditunjukkan oleh Gambar 5 digunakan untuk menambah, mengubah maupun menghapus pengguna sistem, laman ini hanya bisa diakses oleh admin. Laman ubah profil seperti terlihat pada Gambar 6 berfungsi untuk mengubah kata kunci pengguna. Laman kepakaran seperti terlihat pada Gambar 7 digunakan oleh dosen untuk mengubah data kepakaran. Laman kepakaran dosen seperti Gambar 8 digunakan oleh prodi untuk melihat kepakaran dosen dalam prodi tersebut.

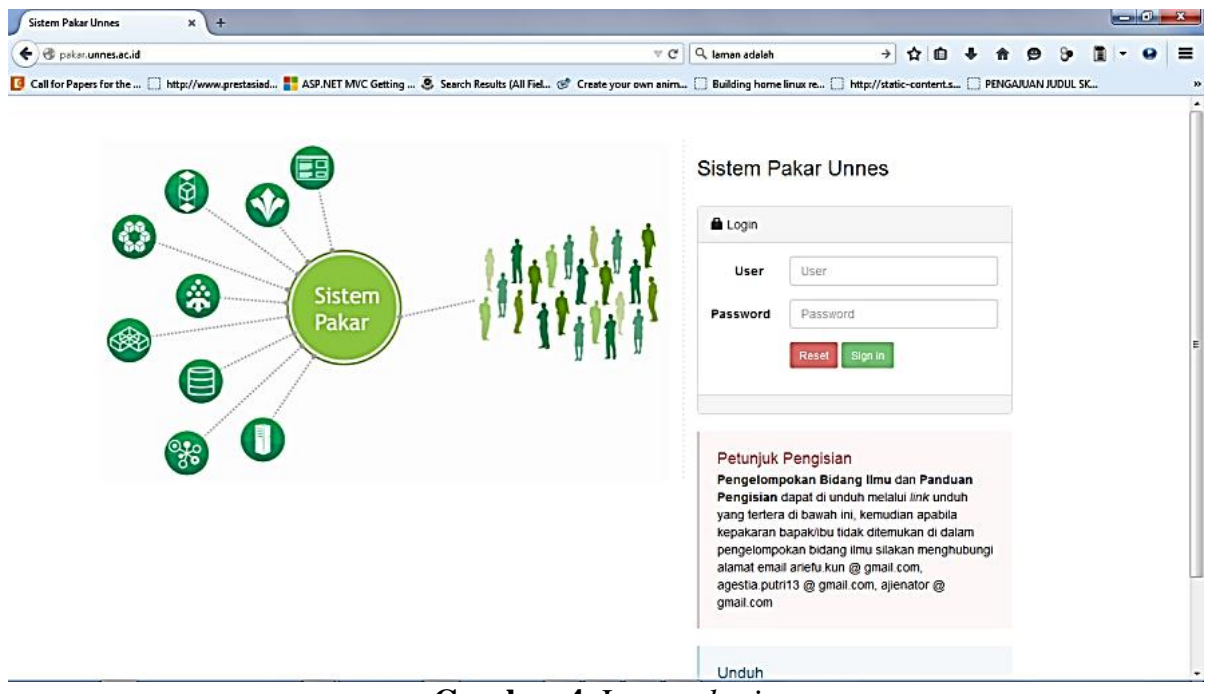

Gambar 4. Laman login

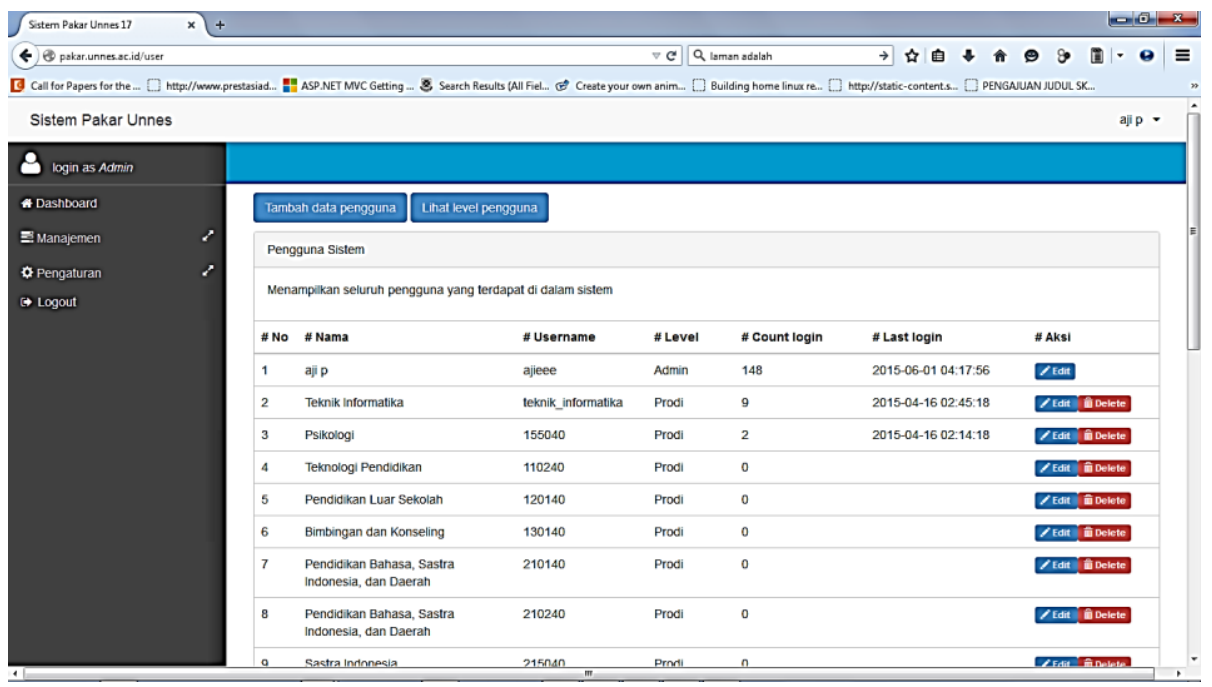

Gambar 5. Laman pengguna 


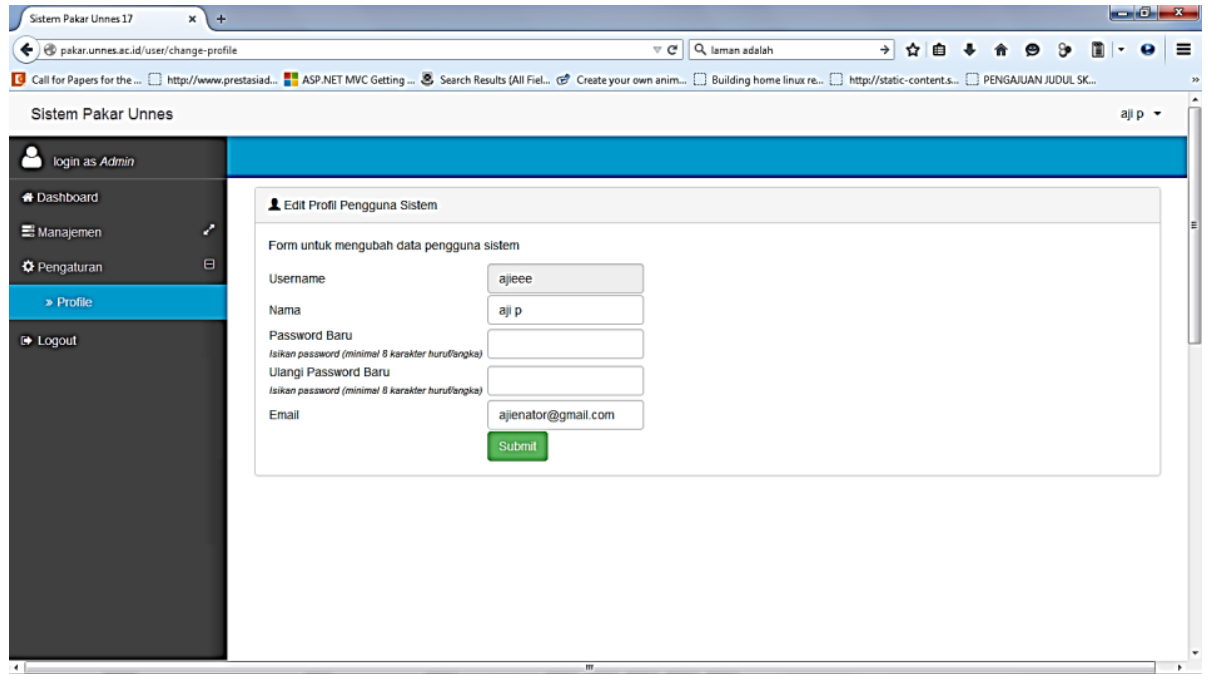

Gambar 6. Laman profil

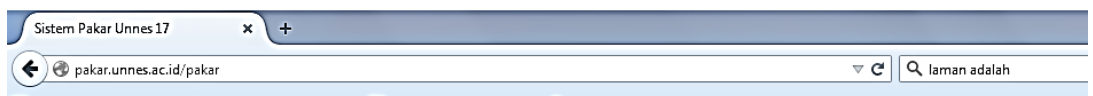

[0. Call for Papers for the ... hi. http://wmw.prestasiad...

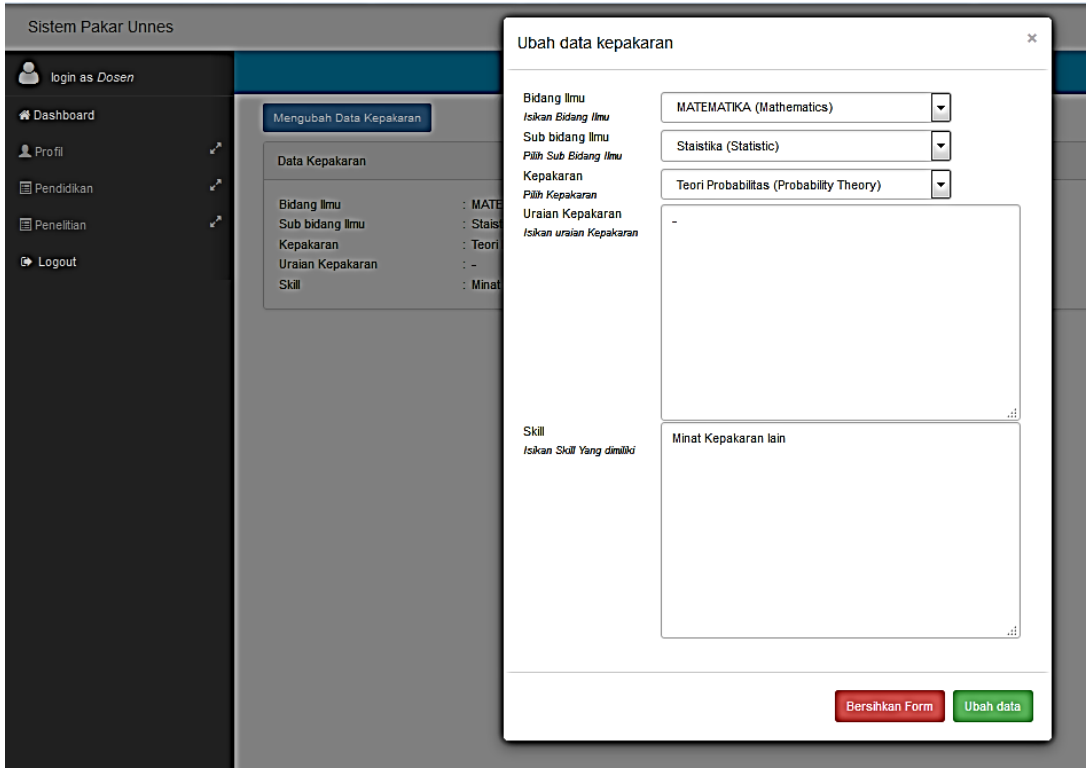

Gambar 7. Laman kepakaran 


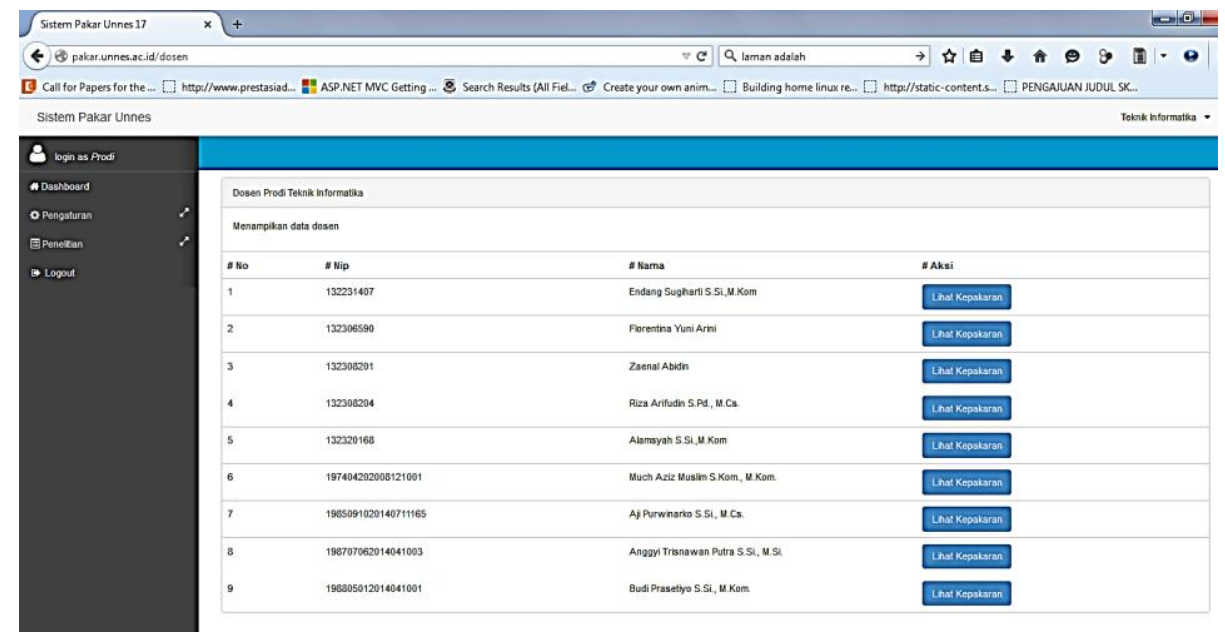

Gambar 8. Kepakaran dosen

\section{SIMPULAN}

Berdasakan hasil penelitian ini disimpulkan bahwa EMS dapat mendokumentasikan kepakaran seorang dosen, sehingga membantu end user untuk menelusuri dosen dengan kepakaran tertentu.

Penelusuran dalam penelitian ini dapat dikembangkan dengan menghubungkan dengan hasil publikasi atau karya ilmiah dosen, sehingga akan mendapatkan kepakaran dosen yang lebih akurat.

\section{REFERENSI}

[1] Sharma, NK. 2012. Management Information System. International Journal of Management, IT and Engineering. Vol. 2: 553-570.

[2] Bapat, HB., Soni, V. 2015. Management Information System: Are you missing the Bus?(A Case Research).

[3] Echols, JM., Shadily, H. 2000. Kamus Inggris-Indonesia. Gramedia, Jakarta.

[4] Merriam-Webster. 2004. Merriam-Webster's collegiate dictionary. MerriamWebster.

[5] Ackerman MS, McDonald D, Lutters W, Muramatsu J. 1999. Recommenders for expertise management. Workshop on" Recommender Systems: Algorithms and Evaluation" at the 1999 ACM International Conference on Research and Development in Information Retrieval (SIGIR'99). Sigir, 1999.

[6] Varshney, KR., Chenthamarakshan, V., Fancher, SW., Wang, J., Fang, D., Mojsilović. 2014. A.: Predicting employee expertise for talent management in the enterprise. Proceedings of the 20th ACM SIGKDD. International conference on Knowledge discovery and data mining. ACM, 2014.

[7] Pressman, RS. 2002. Rekayasa Perangkat Lunak II edn. Andi, Yogyakarta.

[8] Sommerville, I. 2003. Software Engineering 6 edn. Erlangga, Jakarta.

[9] A.S. R, Shalahuddin M. 2013. Rekayasa Perankat Lunak Terstruktur dan Berorientasi Objek. Informatika, Bandung. 
Aji Purwinarko, YL Sukestiyarno

[10] Kadir A. 2008. Dasar Perancangan \& Implementasi Database Relasi 1 edn. Andi, Yogyakarta.

[11] Fathansyah. 2007. Basis Data. Informatika, Bandung. 